\title{
Recent achievements in transcatheter closure of ventricular septal defects: a systematic review of literature and a meta-analysis
}

Piotr Weryński, Paweł Skorek, Agnieszka Wójcik, Anna Rudek-Budzyńska, Aleksandra Dziewulska, Andrzej Rudziński

Department of Pediatric Cardiology, Polish-American Institute of Pediatrics, Jagiellonian University, Medical College, Kraków, Poland

\author{
KEY WORDS \\ complete \\ atrioventricular block \\ interventional \\ cardiology, \\ interventional septal \\ defect closure, \\ ventricular septal \\ defect
}

Correspondence to: Piotr Weryński, MD, PhD Department of Pediatric Cardiology, Polish-American Institute of Pediatrics, Jagiellonian University Medical College, ul. Wielicka 265, 30-663 Kraków, Poland, phone: +48126581390 email: piotr.werynski@uj.edu.pl Received: September 21, 2020. Revision accepted: December 1, 2020. Published online: December 11, 2020. Kardiol Pol. 2021; 79 (2): 161-169 doi:10.33963/KP.15708 Copyright by the Author(s), 2021

\begin{abstract}
BACKGROUND Ventricular septal defect (VSD) is one of the most common congenital heart defects. Currently, surgery remains the treatment of choice. However, transcatheter techniques for closing of various types of VSDs have become an alternative.

AIMS The objective of our study was to present the outcomes of transcatheter closure of various types of VSD based on a systematic review of recent publications.

METHODS A systematic review of studies published in English between January 2014 and March 2020 was performed using the PubMed database (MEDLINE) independently by 2 reviewers. Data on success and complication rates were extracted. Studies including fewer than 5 patients and those with acquired VSD were excluded from the analysis.

RESULTS Finally, 44 studies were included for analysis, with a total number of 4050 patients. The pooled estimate of the overall success rate based on the random effects model was $97.96 \%$ (95\% CI, 97.37-98.56; $Q$ test $P<0.001 ; I^{2}=50 \%$ ). Early residual shunt was the most common complication with a pooled estimate rate of 22.25\% (95\% CI, 16.46-28.05; $\left.P<0.001 ; I^{2}=95 \%\right)$. However, only 92 patients had permanent VSD. Complete atrioventricular block constituted the most dangerous complication, and the pooled estimate rates were assessed as $0.64 \%$ (95\% CI, $\left.0.39-0.88 ; I^{2}=0 \%\right)$ for transient VSD and $0.32 \%$ (95\% CI, 0.15-0.49; $P>0.99 ; I^{2}=0 \%$ ) for permanent VSD.

CONCLUSIONS Transcatheter closure of selected VSDs appears to be an effective and safe method of treatment. Recent studies have shown high rates of successful interventions with a low incidence of complications.
\end{abstract}

INTRODUCTION Ventricular septal defect (VSD) is one of the most common (41.6\%) congenital heart defects. ${ }^{1}$ It may occur as a solitary defect, multiple openings, or part of complex cardiovascular malformations. Considering VSD borders, the condition can be classified as perimembranous (pmVSD; 75\%), muscular (mVSD; 20\%), or subarterial (about 5\%). ${ }^{1}$ Among mVSDs, there are trabecular defects located in the anterior, mid, posterior, or apical part of the ventricular septum. Posterior mVSD differs from perimembranous inlet VSD (so-called atrioventricular canal-type defect) by the presence of a superior muscular rim just below the septal leaflet of the tricuspid valve, which is absent in the latter.
Defects in which the conal septum is rotated out of the remainder of the muscular ventricular septum are called malalignment VSDs. Sporadically, a specific type of VSD in the membranous part of the ventricular septum (above the tricuspid valve) may occur, causing a direct shunt from the left ventricle to the right atrium, named Gerbode defect. Despite the location, VSDs vary in size, which determines the clinical course and management of the disease. Even small VSDs may require treatment due to unfavorable position (eg, subaortic).

Currently, open heart surgery remains the treatment of choice for symptomatic VSDs. However, a standard transatrial or transarterial 


\section{WHAT'S NEW?}

Our review summarized recent outcomes of transcatheter closure of various types of ventricular septal defects reported in the literature between January 2014 and March 2020. To our best knowledge, the last similar review was published in 2017. Since then, a significant number of relevant papers has been published. Unlike in previous reviews, we classified the incidence of complete atrioventricular block as transient or chronic, considering a notably different clinical significance of both types. Our study showed high rates of successful interventions with an acceptable incidence of complications. This is the first such analysis in the Polish medical literature.

surgical approach may be problematic in some cases. This particularly applies to VSDs in which it is difficult to obtain surgical access and extensive ventriculotomy or postoperational residual shunts (RSs) are required. Previous reports on the outcomes of surgical VSD treatment have shown a significant risk of RS, early and late cardiac arrhythmias, conduction disturbances, prolonged hospitalization time, as well as increased hospital morbidity and mortality ranging between $1.4 \%$ and $2.17 \% .^{2}$ In addition, a negative psychological impact of surgical trauma and scars should be considered. For this reason, transcatheter techniques for closing of various types of VSDs have become a helpful alternative, which allows us to avoid or supplement the operation. Risks associated with this treatment method include: device migration or embolism, aortic or tricuspid valve regurgitation, hemolysis, transient ischemic stroke, cardiac arrhythmia, rarely complete atrioventricular block (CAVB), and intraventricular conduction disturbances. ${ }^{3,4}$

Since the first percutaneous transcatheter closure of VSD was performed, technical advances and the number of various types of occluders along with experience in their use have significantly increased. ${ }^{1}$ Based on a systematic review of recent publications, we aimed to present the outcomes of transcatheter closure of various types of VSD. Such analysis could be helpful in everyday practice of a wide range of clinicians.

METHODS A systematic review of studies published in English between January 2014 and March 2020 was performed using the PubMed database (MEDLINE) with the following terms searched: "transcatheter ventricular septal defect closure," "interventional septal defect closure," and "ventricular septal defect." From this search list, studies that fulfilled the predetermined criteria were selected independently by 2 reviewers and entered into an electronic database. Prospective and retrospective (randomized and nonrandomized) studies reporting data on transcatheter closure of any type of congenital VSD, using any type of device, and with well-defined follow-up (based on electrocardiographic and echocardiographic assessments) were included. We excluded single-case studies, series of cases of fewer than 5 patients, and studies on acquired post-myocardial infarction or posttraumatic VSD. Studies without follow-up or with a significant lack of data were also excluded. To avoid potential duplicate or overlapping results, the list of all studies selected in the first step were reviewed by the 2 previously mentioned authors and another one so far not involved in study selection. In that step, 3 duplicated studies were found and excluded. The whole detailed process used for study screening and selection is illustrated in the PRISMA flow diagram (Supplementary material, Figure S1). ${ }^{5} \mathrm{Fi}$ nally, out of 312 studies found, 44 were finally considered for analysis. Further information about the type of VSD, devices used, patients' age, follow-up, success rates, as well as types and frequency of complications was extracted by one of the authors and entered into an electronic database. Successful implantation was defined as correct and stable placement with satisfactory effects confirmed by imaging. The success rate was obtained from the articles that featured this information or otherwise calculated. Of valvular lesions, only a new onset of aortic or tricuspid regurgitation was considered. Complications were regarded as permanent if they remained present at the time of the latest follow-up. A complication was considered early if it appeared during procedure-related hospitalization. The approval of an ethical committee was waived because of the study design (a review of published studies).

Statistical analysis To address the possibility of publication bias, a funnel plot of sample size was generated against the success rate of each study. The random effect model and the empirical Bayes method were used to obtain pooled estimates of rates of success and various types of complications. ${ }^{6,7}$ It was postulated that the 44 studies represented a random sample from the larger population of such studies, with each study having its own underlying effect size. This model assumes that there is a mean population effect size with regard to which study-specific effect varies. Heterogeneity among studies was evaluated using the inconsistency statistic. A 2-sided proportion test from the OpenMetaAnalyst software was used for statistical analysis. ${ }^{7}$ For all tests, a $P$ value less than 0.05 was considered significant. The funnel plot was created using the MedCalc software, version 19.3.1 (MedCalc Software, Ltd., Ostend, Belgium).

RESULTS Finally, 44 studies $^{8-51}$ were analyzed, with a total number of 4050 patients (Supplementary material, Table S2). The years 2018 and 2019 prevailed in the number of publications 


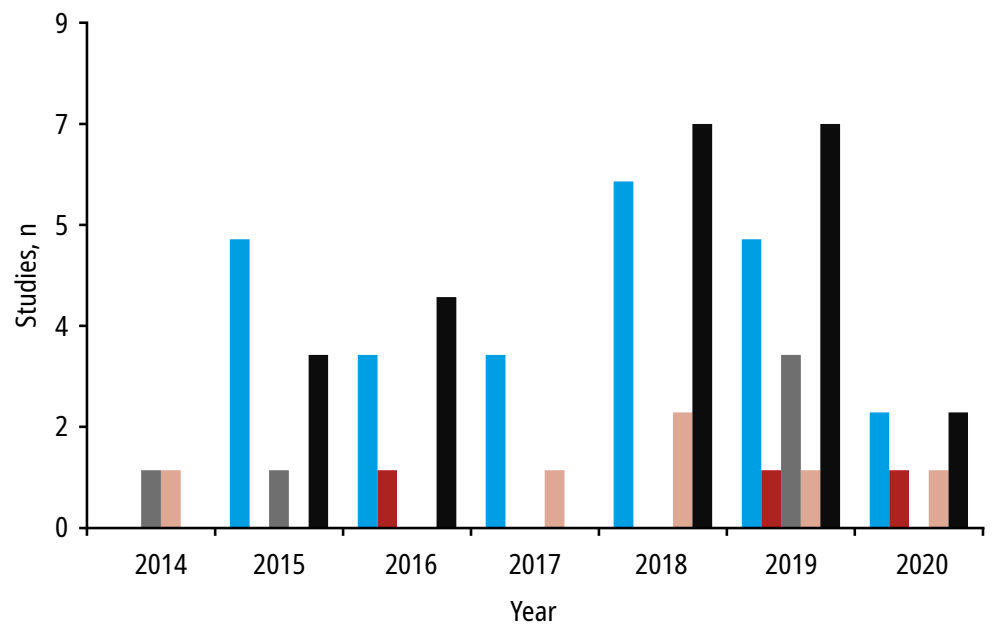

- ADO $\quad$ AVP $\quad$ Other Amplatzer devices $\square$ NitOcclud Lê VSD coil $\square$ Other

FIGURE 1 Devices used in each analyzed year

Abbreviations: ADO, Amplatzer Duct Occluder; AVP, Amplatzer Vascular Plug

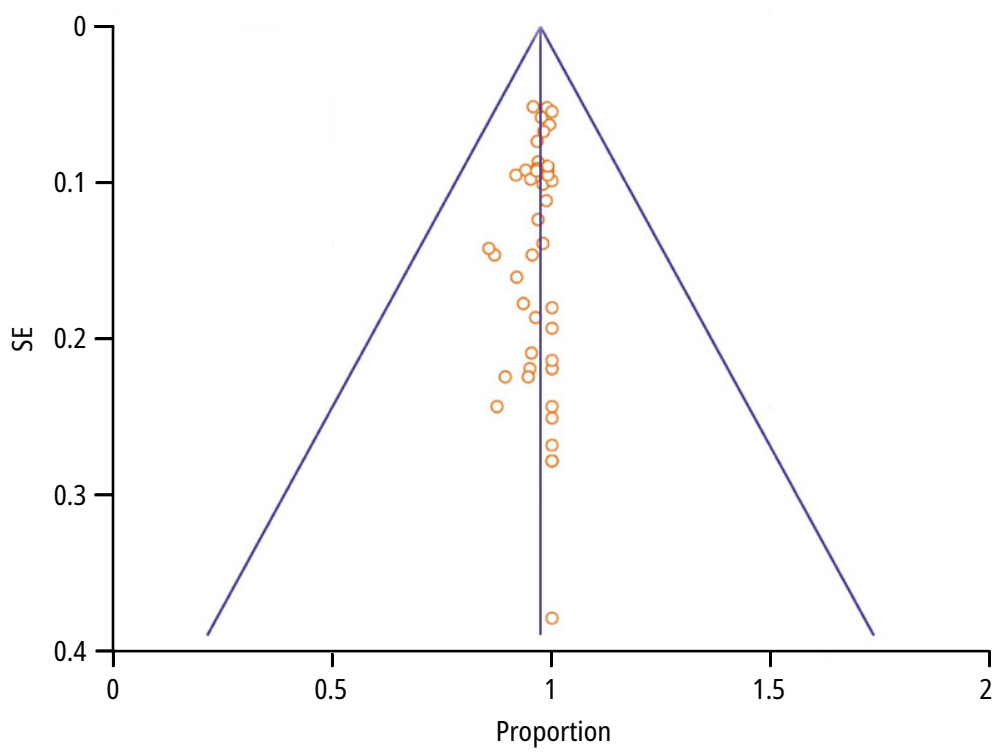

FIGURE 2 Funnel plot of interventional success rates

(10 each year; 22.73\%) (Supplementary material, Table S2). Types of devices used in studies through the analyzed years are presented in FIGURE1. The Amplatzer Duct Occluder (ADO) was one of the most commonly used instruments (in 24 studies; FIGURE 1). Most studies included pediatric populations with a small proportion of adults, at age ranging between 13 days to 65.6 years. ${ }^{33,39}$ Narin et $\mathrm{l}^{28}$ reported 12 cases of successful intervention in the population under 1 year of age (range, 2-12 months). Moreover, Pillai et a ${ }^{17}$ conducted a study in a group of 49 children weighing up to $10 \mathrm{~kg}$, at a median (interquartile range) age of 18 (13-22) months. Perimembranous VSD was the most common type of defect observed (3812 patients in 38 out of 45 studies). Muscular VSD was described in 66 cases (8 studies), postoperative or residual VSD, in 41 cases (7 studies), and 131 patients had other types of VSD (85 cases of intracristal VSD, 24 of doubly committed VSD, and 14 of Gerbode defect, among others). The median duration of follow-up ranged from 6.5 to 110 months (Supplementary material, Table S2). ${ }^{14,41}$ A total of 40 out of 44 studies (90.91\%) reported a success rate exceeding $90 \%$. To assess the risk of publication bias, a funnel plot was constructed (FIGURE 2) without any obvious funnel asymmetry. The pooled estimate of the overall success rate based on the random effects model was $97.96 \%$ (95\% CI, 97.37-98.56; FIGURE 3). However, the Q statistic showed a significant heterogeneity $\left(P<0.001 ; I^{2}=50 \%\right)$ for that result.

Early residual shunt, reported in 640 cases $(15.8 \%)$ in 39 studies, constituted the most common complication. Its pooled estimate rate was $22.25 \%$ (95\% CI, 16.46-28.05; Q test $P<0.001 ; I^{2}=95 \%$; FIGURE 4). However, only 92 residual shunts (in 29 studies) were present at the last follow-up visit and regarded as permanent, with a pooled estimate rate of $2.11 \%$ (95\% CI, 1.24-2.97; Q test $P<0.001 ; I^{2}=52 \%$ ). In 15 studies, no residual shunt was found at the last follow-up visit. In well-documented control studies, Haas et $\mathrm{al}^{35}$ showed that complete VSD closure occurred in 90 of 101 patients at 3 months, 93 of 98 at 6 months, 94 of 97 at 12 months, 82 of 83 at 18 months, 67 of 68 at 24 months, 31 of 31 at 36 months, and 16 of 16 at 48 months. The highest documented rate of permanent residual shunt was $23.08 \%$. $^{24}$

Next, the occurrence of CAVB was assessed. In this review, in most cases, CAVB was transient, with an incidence of 35 events in 21 studies. Its pooled estimate rate was $0.64 \%$ (95\% CI, 0.39-0.88; Q test $P>0.99 ; I^{2}=0 \%$; FIGURE 5). According to reported data, $C A V B$ resolved in 10 cases (28.57\%) after steroid-only treatment. However, there were 12 cases (in 8 studies) of permanent CAVB with a pooled estimate rate of $0.32 \%$ (95\% CI, 0.15-0.49; Q test $P>0.99 ; I^{2}=0 \%$; FIGURE 6). The highest reported incidence of this complication was $8.33 \%$ (a single patient among 12 individuals). ${ }^{28}$ An interesting case was described by Haddad et al, ${ }^{14}$ wherein CAVB occurred immediately after the device was released, but sinus rhythm returned 5 minutes after intravenous bolus administration of atropine and steroids. It was classified as transient, and the patient was discharged in a good condition. After 18 months, the presence of $C A V B$ was again revealed during a routine follow-up visit and the patient required permanent pacemaker implantation.

The postprocedural occurrence of tricuspid and aortic valve regurgitation is summarized in TABLE1. The highest reported incidence of early tricuspid valve regurgitation was $25.49 \%$ (26 of 102 patients). ${ }^{29}$ However, it was $40.91 \%$ (9 of 22 patients) for aortic valve regurgitation. ${ }^{18}$ A review of reports showed a decrease in the incidence of these lesions over time, more frequently involving the tricuspid 


\begin{tabular}{|c|c|c|}
\hline Mijangos-Vázquez et al ${ }^{8}$ & $0.99(0.98-1)$ & $118 / 119$ \\
\hline Tanidir et al ${ }^{9}$ & $0.98(0.95-1)$ & $96 / 98$ \\
\hline Shah et al ${ }^{10}$ & $0.99(0.98-1)$ & $372 / 376$ \\
\hline Houeijeh et al ${ }^{11}$ & $0.87(0.77-0.97)$ & $40 / 46$ \\
\hline Haddad et al ${ }^{12}$ & $0.98(0.91-1)$ & $20 / 20$ \\
\hline Li et al ${ }^{13}$ & $0.99(0.99-1)$ & $252 / 253$ \\
\hline Haddad et al ${ }^{14}$ & $0.98(0.94-1)$ & $50 / 51$ \\
\hline Bu et al ${ }^{15}$ & $0.96(0.9-1)$ & $44 / 46$ \\
\hline Kouakou et al ${ }^{16}$ & $0.93(0.74-1)$ & $6 / 6$ \\
\hline Pillai et al ${ }^{17}$ & $0.86(0.76-0.96)$ & $42 / 49$ \\
\hline Huang et al ${ }^{18}$ & $0.96(0.87-1)$ & $21 / 22$ \\
\hline Shrestha et al ${ }^{19}$ & $0.97(0.94-0.99)$ & $129 / 133$ \\
\hline Udink Ten Cate et al20 & $0.98(0.96-0.99)$ & $218 / 222$ \\
\hline He et $a^{21}$ & $0.98(0.91-1)$ & $20 / 20$ \\
\hline Esmaeili et al22 & $0.97(0.88-1)$ & $15 / 15$ \\
\hline Wang et $\mathrm{a}^{23}$ & $0.94(0.9-0.98)$ & $111 / 118$ \\
\hline Park et al ${ }^{24}$ & $0.96(0.87-1)$ & $13 / 13$ \\
\hline Ghosh et al25 & $0.86(0.76-1)$ & $17 / 19$ \\
\hline Nguyen et $a^{26}$ & $0.96(0.94-0.98)$ & $370 / 386$ \\
\hline Mandal et $\mathrm{al}^{27}$ & $0.97(0.94-0.99)$ & $180 / 186$ \\
\hline Narin et al28 & $0.96(0.86-1)$ & $12 / 12$ \\
\hline Zhao et al ${ }^{29}$ & $0.995(0.98-1)$ & $102 / 102$ \\
\hline El Shedoudy et al ${ }^{30}$ & $0.99(0.96-1)$ & $79 / 80$ \\
\hline He et $a 1^{31}$ & $0.97(0.94-0.999)$ & $117 / 121$ \\
\hline Lin et al 32 & $0.95(0.91-0.99)$ & $100 / 105$ \\
\hline Shyu et al ${ }^{33}$ & $0.86(0.71-1)$ & $14 / 16$ \\
\hline El-Sisi et al ${ }^{34}$ & $0.98(0.94-1)$ & $30 / 30$ \\
\hline Haas et al ${ }^{35}$ & $0.92(0.87-0.97)$ & $102 / 111$ \\
\hline Zhou et al ${ }^{36}$ & $0.96(0.86-1)$ & $12 / 12$ \\
\hline Hua et al ${ }^{37}$ & $0.97(0.89-1)$ & $16 / 16$ \\
\hline Thakkar et al ${ }^{38}$ & $0.98(0.96-0.99)$ & $290 / 297$ \\
\hline Polat et al ${ }^{39}$ & $0.98(0.93-1)$ & $26 / 26$ \\
\hline Wang et al 40 & $0.999(0.99-1)$ & $337 / 337$ \\
\hline Bai et al41 & $0.97(0.93-0.999)$ & 113/117 \\
\hline Ghaderian et al ${ }^{42}$ & $0.99(0.97-1)$ & $109 / 110$ \\
\hline Chen et al ${ }^{43}$ & $0.92(0.84-1)$ & $35 / 38$ \\
\hline Ghaderian et al ${ }^{44}$ & $0.96(0.9-1)$ & $27 / 28$ \\
\hline Chen et al ${ }^{45}$ & $0.97(0.93-1)$ & $63 / 65$ \\
\hline Mahimarangaiah et al ${ }^{46}$ & $0.99(0.98-1)$ & $125 / 126$ \\
\hline Kanaan et al47 & $0.94(0.85-1)$ & $29 / 31$ \\
\hline Vijayalakshmi et al ${ }^{48}$ & $0.96(0.86-1)$ & $12 / 12$ \\
\hline Narin et al ${ }^{49}$ & $0.98(0.92-1)$ & $21 / 21$ \\
\hline Odemis et al ${ }^{50}$ & $0.95(0.85-1)$ & $19 / 20$ \\
\hline Tzikas et al ${ }^{51}$ & $0.95(0.85-1)$ & $18 / 19$ \\
\hline $\begin{array}{l}\text { Overall }\left(I^{2}=50 \% \text {; }\right. \\
P<0.001)\end{array}$ & $0.98(0.974-0.986)$ & $3942 / 4050$ \\
\hline
\end{tabular}

\section{ra}

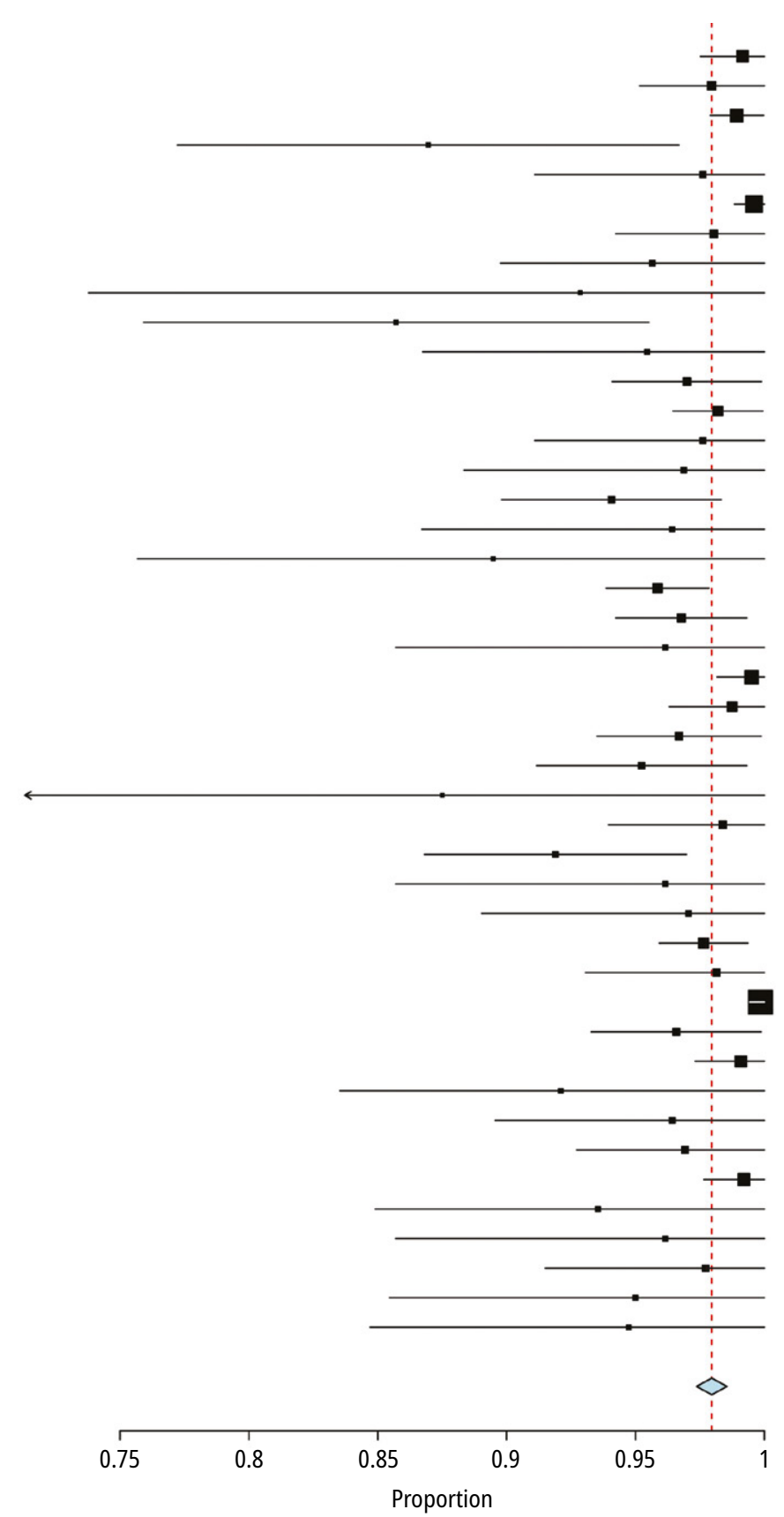

FIGURE 3 Forrest plot of interventional success rates

valve. The pooled estimate rate for mild or lower tricuspid valve regurgitation in the last follow-up period was $1.92 \%$ (95\% CI, 0.91-2.94; Q test $P<0.001$; $\left.I^{2}=52 \%\right)$, and $1.15 \%$ for aortic valve regurgitation (95\% CI, 0.47-1.82; Q test $P=0.03 ; I^{2}=30 \%$ ).

Hemolysis occurred in 39 cases documented in 10 reports. Most of them were described as mild and transient, but 6 cases required early surgical intervention. The pooled estimate rate for its incidence was $0.52 \%$ (95\% CI, $0.29-0.74$; $Q$ test $\left.P=0.65 ; I^{2}=0 \%\right)$. In the study with the highest rate, 8 cases of hemolysis occurred in the periprocedural period (4 were transient and self-limiting and 4 required blood transfusion). ${ }^{11}$
DISCUSSION Cardiac surgery has had an established position in the treatment of VSD for years, and, in some VSD types, it represents the treatment of choice. However, according to the newest 2020 European Society of Cardiology guidelines, transcatheter VSD closure has become an alternative, particularly in residual VSDs, VSDs poorly accessible by surgery, and in mVSDs located centrally in the interventricular septum. ${ }^{52}$ It has also been deemed feasible in pmVSD. ${ }^{52}$ Moreover, this procedure has significant advantages such as shorter hospitalization, faster recovery time, possibility to avoid cardiopulmonary bypass, lower incidence rates for some complications compared with surgery, and weaker psychological impact. ${ }^{53}$ 


\begin{tabular}{|c|c|c|}
\hline Mijangos-Vázquez et al ${ }^{8}$ & $0.13(0.07-0.2)$ & $16 / 119$ \\
\hline Tanidir et $\mathrm{al}^{9}$ & $0.13(0.07-0.2)$ & $13 / 98$ \\
\hline Shah et al $^{10}$ & $0.04(0.02-0.06)$ & $14 / 376$ \\
\hline Houeijeh et al ${ }^{11}$ & $0.35(0.21-0.49)$ & $16 / 46$ \\
\hline Haddad et al ${ }^{12}$ & $0.6(0.39-0.82)$ & $12 / 20$ \\
\hline Li et al ${ }^{13}$ & $0.13(0.09-0.172)$ & $33 / 253$ \\
\hline Haddad et al ${ }^{14}$ & $0.67(0.84-0.8)$ & $34 / 51$ \\
\hline Bu et $\mathrm{al}^{15}$ & $0.02(0-0.06)$ & $1 / 46$ \\
\hline Kouakou et al ${ }^{16}$ & $0.5(0.1-0.9)$ & $3 / 6$ \\
\hline Pillai et al ${ }^{17}$ & $0.22(0.1-0.34)$ & $11 / 49$ \\
\hline Huang et $\mathrm{al}^{18}$ & $0.5(0.29-0.71)$ & $11 / 22$ \\
\hline Shrestha et al ${ }^{19}$ & $0.31(0.23-0.39)$ & $41 / 133$ \\
\hline Udink Ten Cate et al20 & $0.08(0.05-0.12)$ & $18 / 222$ \\
\hline He et $\mathrm{al}^{21}$ & $0.02(0-0.09)$ & $0 / 20$ \\
\hline Esmaeili et al22 & $0.27(0.04-0.5)$ & $4 / 15$ \\
\hline Wang et $\mathrm{al}^{23}$ & $0.08(0.03-0.12)$ & $9 / 118$ \\
\hline Park et al ${ }^{24}$ & $0.54(0.27-0.81)$ & $7 / 13$ \\
\hline Ghosh et al ${ }^{25}$ & $0.03(0-0.09)$ & $0 / 19$ \\
\hline Nguyen et $\mathrm{al}^{26}$ & $0.25(0.21-0.3)$ & $98 / 386$ \\
\hline Mandal et al27 & $0.01(0-0.02)$ & $1 / 186$ \\
\hline Narin et $\mathrm{al}^{28}$ & $0.33(0.07-0.6)$ & $4 / 12$ \\
\hline Zhao et al ${ }^{29}$ & $0.17(0.09-0.24)$ & $17 / 102$ \\
\hline El Shedoudy et a ${ }^{30}$ & $0.38(0.27-0.48)$ & $30 / 80$ \\
\hline He et $a l^{31}$ & $0.004(0-0.02)$ & $0 / 121$ \\
\hline Lin et $\mathrm{al}^{32}$ & $0.09(0.03-0.14)$ & $9 / 105$ \\
\hline Shyu et al ${ }^{33}$ & $0.31(0.09-0.54)$ & $5 / 16$ \\
\hline El-Sisi et al ${ }^{34}$ & $0.13(0.01-0.26)$ & $4 / 30$ \\
\hline Haas et al ${ }^{35}$ & $0.46(0.37-0.55)$ & $51 / 111$ \\
\hline Zhou et $\mathrm{al}^{36}$ & $0.17(0-0.38)$ & $2 / 12$ \\
\hline Hua et $\mathrm{al}^{37}$ & $0.69(0.46-0.92)$ & $11 / 16$ \\
\hline Thakkar et al ${ }^{38}$ & $0.11(0.07-0.14)$ & $32 / 297$ \\
\hline Polat et al ${ }^{39}$ & $0.19(0.04-0.34)$ & $5 / 26$ \\
\hline Wang et al ${ }^{40}$ & $0.03(0.01-0.05)$ & $11 / 337$ \\
\hline Bai et al ${ }^{41}$ & $0.07(0.02-0.11)$ & $8 / 117$ \\
\hline Ghaderian et al ${ }^{42}$ & $0.26(0.18-0.35)$ & $29 / 110$ \\
\hline Chen et $\mathrm{al}^{43}$ & $0.11(0.01-0.2)$ & $4 / 38$ \\
\hline Ghaderian et al ${ }^{44}$ & $0.32(0.15-0.49)$ & $9 / 28$ \\
\hline Mahimarangaiah et al ${ }^{46}$ & $0.29(0.21-0.37)$ & $37 / 126$ \\
\hline Kanaan et $\mathrm{a}^{47}$ & $0.32(0.16-0.49)$ & $10 / 31$ \\
\hline Vijayalakshmi et al48 & $0.04(0-0.14)$ & $0 / 12$ \\
\hline Narin et al ${ }^{49}$ & $0.14(0-0.29)$ & $3 / 21$ \\
\hline Odemis et al ${ }^{50}$ & $0.15(0-0.31)$ & $3 / 20$ \\
\hline Tzikas et al ${ }^{51}$ & $0.74(0.54-0.94)$ & $14 / 19$ \\
\hline $\begin{array}{l}\text { Overall }\left(I^{2}=95 \% ;\right. \\
P<0.001)\end{array}$ & $0.22(0.17-0.28)$ & \\
\hline
\end{tabular}

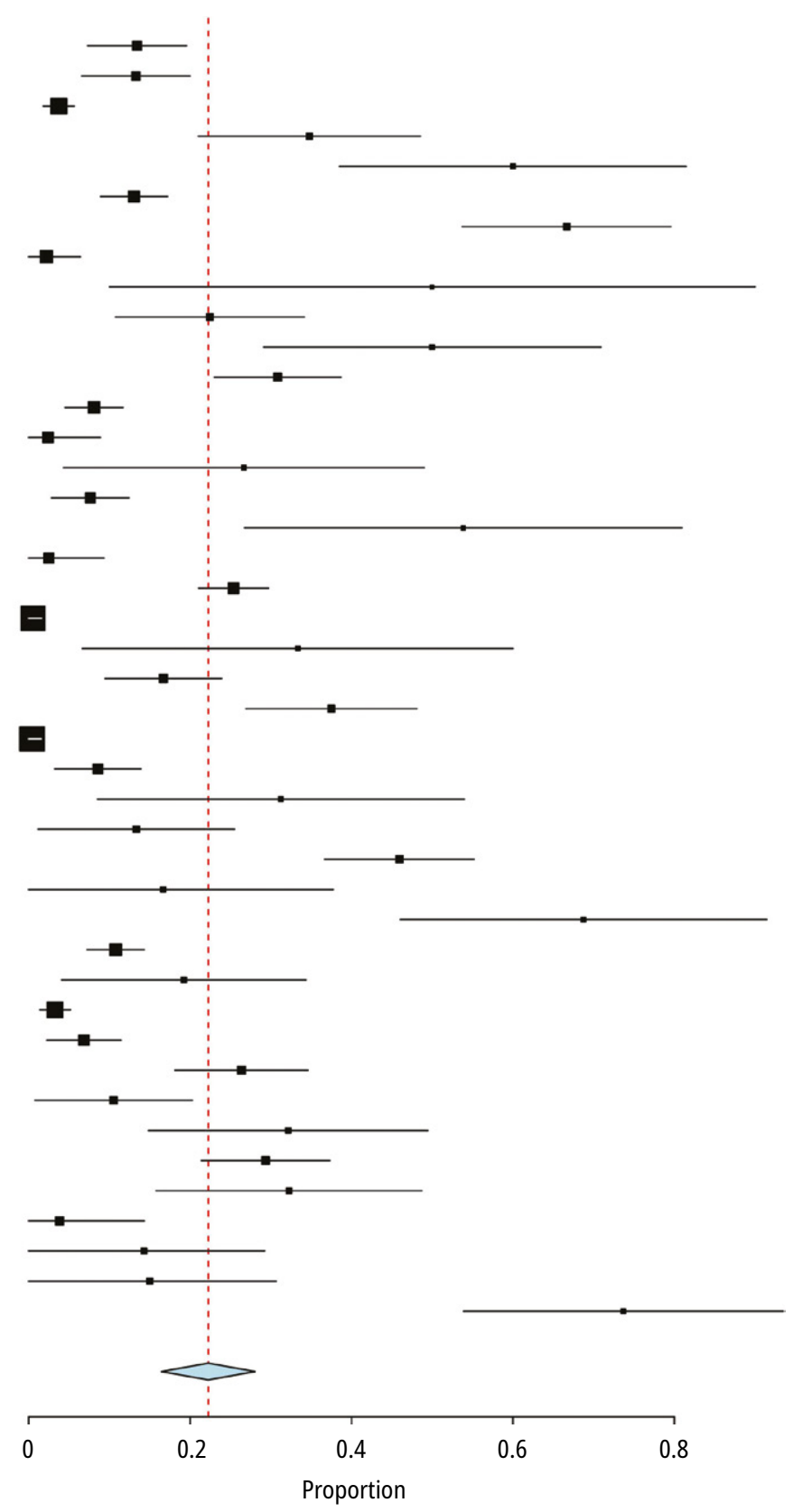

FIGURE 4 Forrest plot of early residual shunt occurrence

On the other hand, complications of percutaneous VSD closure, such as various cardiac arrhythmias and $C A V B$, valvular disease, excessive bleeding, embolic risk, injury to the manipulated blood vessels, and hematoma formation in the groin, can be resolved..$^{3,4}$ Therefore, the use of transcatheter versus surgical procedures still requires weighing risks and benefits associated with each method, considering the type and size of VSD, patients' age and weight, available equipment, and experience of the catheterization laboratory team.

In this systematic review, we attempted to evaluate whether transcatheter closure of the selected types of VSD in pediatric patients is an effective method of treatment, in terms of not only the success rate but also safety of the procedure. The high pooled estimate of the overall success rate of implantation $(97.96 \%$; 95\% CI, 97.37-98.56) in our review suggests that most devices have been successfully deployed with good outcomes leading to VSD closure. Similar results were reported in analyses conducted by Santhanam et $\mathrm{al}^{3}$ (97.8\%; 95\% CI, 96.8-98.6) and Yang et $\mathrm{al}^{4}$ (96.6\%; 95\% CI, 95.7-97.5). These results may also suggest a certain increase in the effectiveness of the method over the years. Failures were mainly associated with large RSs, instability of selected devices, or serious complications such as CAVB or embolization. ${ }^{8-51}$ 
Mijangos-Vázquez et al ${ }^{8}$

Tanidir et al ${ }^{9}$

Shah et al ${ }^{10}$

Houeijeh et al ${ }^{11}$

Haddad et al ${ }^{12}$

Li et al ${ }^{13}$

Haddad et al ${ }^{14}$

Bu et a ${ }^{15}$

Kouakou et al ${ }^{16}$

Pillai et al ${ }^{17}$

Huang et al ${ }^{18}$

Shrestha et al ${ }^{19}$

Udink Ten Cate et al ${ }^{20}$

He et al ${ }^{21}$

Esmaeili et al ${ }^{22}$

Wang et $\mathrm{a}^{23}$

Park et al ${ }^{24}$

Ghosh et a ${ }^{25}$

Nguyen et $\mathrm{al}^{26}$

Mandal et al ${ }^{27}$

Narin et a ${ }^{28}$

Zhao et al ${ }^{29}$

El Shedoudy et $\mathrm{al}^{30}$

He et a ${ }^{31}$

Lin et al ${ }^{32}$

Shyu et al ${ }^{33}$

El-Sisi et a ${ }^{34}$

Haas et al ${ }^{35}$

Zhou et a $\left.\right|^{36}$

Hua et al ${ }^{37}$

Thakkar et al ${ }^{38}$

Polat et $\mathrm{a}^{39}$

Wang et a 140

Bai et $\mathrm{a}^{41}$

Ghaderian et al ${ }^{42}$

Chen et al ${ }^{43}$

Ghaderian et al ${ }^{44}$

Chen et al ${ }^{45}$

Mahimarangaiah et $a^{46}$

Kanaan et al ${ }^{47}$

Vijayalakshmi et al ${ }^{48}$

Narin et al 49

Odemis et $\mathrm{al}^{50}$

Tzikas et a ${ }^{51}$

Overall $\left(I^{2}=0 \%\right.$; $P=0.998)$

\section{(95\% CI)}

$\begin{array}{ll}0.008(0-0.03) & 1 / 119 \\ 0.005(0-0.02) & 0 / 98 \\ 0.005(0-0.01) & 2 / 376 \\ 0.011(0-0.04) & 0 / 46 \\ 0.02(0-0.09) & 0 / 20 \\ 0.002(0-0.01) & 0 / 253 \\ 0.02(0-0.06) & 1 / 51 \\ 0.011(0-0.04) & 0 / 46 \\ 0.071(0-0.26) & 0 / 6 \\ 0.02(0-0.06) & 1 / 49 \\ 0.022(0-0.08) & 0 / 22 \\ 0.008(0-0.02) & 1 / 133 \\ 0.005(0-0.01) & 1 / 222 \\ 0.024(0-0.09) & 0 / 20 \\ 0.031(0-0.12) & 0 / 15 \\ 0.02(0-0.04) & 2 / 118 \\ 0.036(0-0.13) & 0 / 13 \\ 0.025(0-0.09) & 0 / 19 \\ 0.013(0.002-0.02) & 5 / 386 \\ 0.005(0-0.02) & 1 / 186 \\ 0.038(0-0.14) & 0 / 12 \\ 0.005(0-0.02) & 0 / 102 \\ 0.012(0-0.04) & 1 / 80 \\ 0.017(0-0.04) & 2 / 121 \\ 0.005(0-0.02) & 0 / 105 \\ 0.03(0-0.11) & 0 / 16 \\ 0.016(0-0.06) & 0 / 30 \\ 0.018(0-0.04) & 2 / 111 \\ 0.04(0-0.14) & 0 / 12 \\ 0.029(0-0.11) & 0 / 16 \\ 0.01(0-0.02) & 3 / 297 \\ 0.019(0-0.07) & 0 / 26 \\ 0.003(0-0.01) & 1 / 337 \\ 0.034(0.001-0.07) & 4 / 117 \\ 0.009(0-0.03) & 1 / 110 \\ 0.026(0-0.08) & 1 / 38 \\ 0.036(0-0.10) & 1 / 28 \\ 0.031(0-0.07) & 2 / 65 \\ 0.008(0-0.02) & 1 / 126 \\ 0.016(0-0.06) & 0 / 31 \\ 0.08(0-0.24) & 1 / 12 \\ 0.023(0-0.09) & 0 / 21 \\ 0.02(0-0.09) & 0 / 20 \\ 0.03(0-0.09 & 0 / 19 \\ 0.006(0.004-0.009) & 35 / 405 \\ & \end{array}$

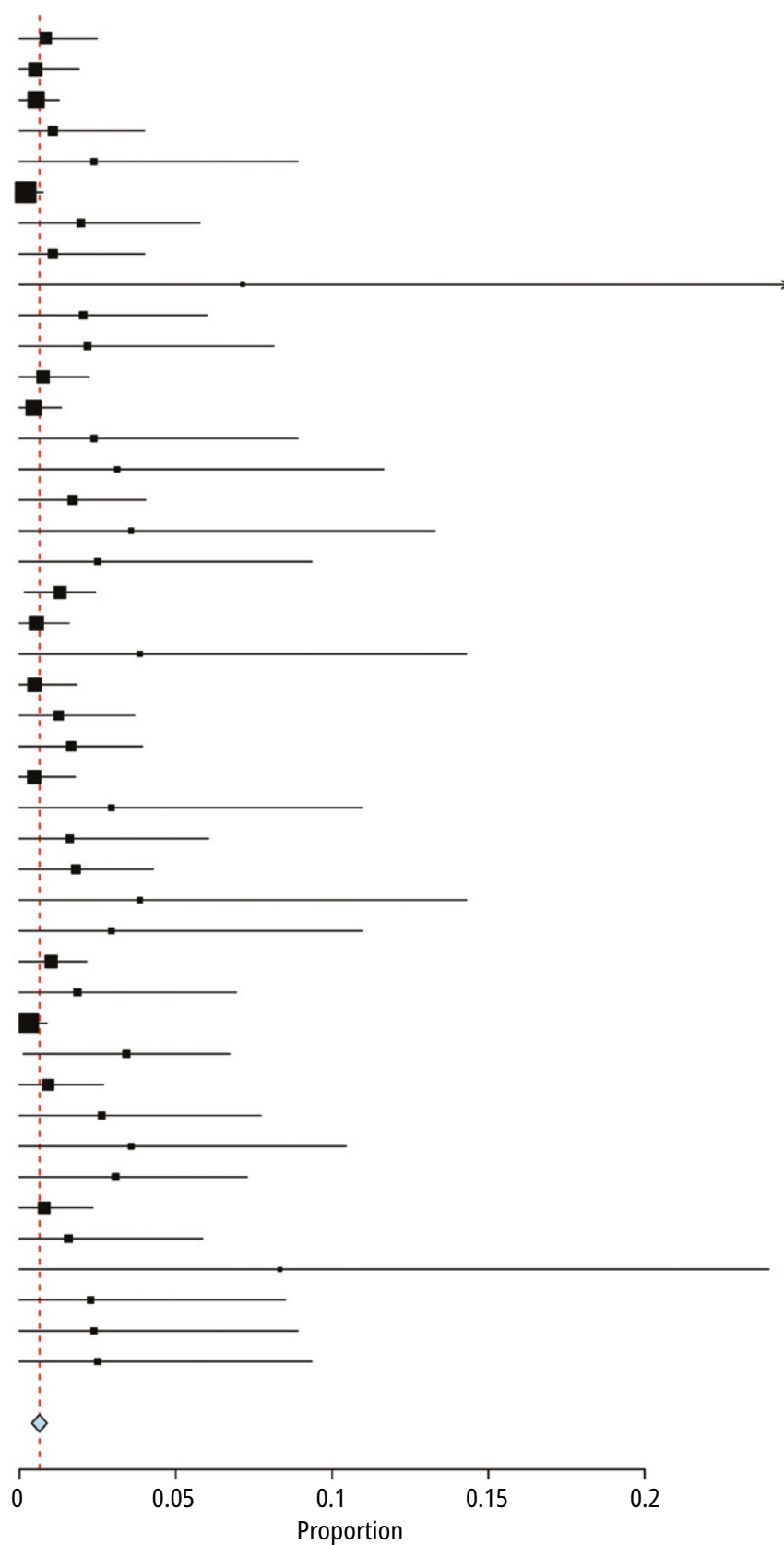

FIGURE 5 Forrest plot of transient complete atrioventricular block occurrence

The presence of RS was the most common complication related to intervention in our review, and other available analyses provided similar observations., ${ }^{3,4}$ Yang et $\mathrm{al}^{4}$ reported findings similar to ours, with the pooled incidence rates of early RS at $25.5 \%$ (95\% CI, 18.9-32.1) and permanent RS at 3.1\% (95\% CI, 2-4.1). However, the corresponding rates in the analysis of Santhanam et $\mathrm{al}^{3}$ were lower: $15.9 \%$ (95\% CI, 10.921.5 ) for early RS, and $1.7 \%$ (95\% CI, 0.8-2.7) for permanent RS.

Permanent CAVB was the most serious complication associated with transcatheter VSD closure. Previous studies have suggested a high, unacceptable incidence (3.8\%) of this dangerous complication. ${ }^{53}$ The 2007 European registry of transcatheter closure of congenital VSDs showed an occurrence rate for CAVB of 5\% after pmVSD closure and $0.8 \%$ after mVSD closure, and for residual post-surgery VSD, at $6.7 \%$. In addition, in 6 cases, CAVB was transient, while in 10 (3.8\%; early in 6, and late in 4 ), a pacemaker was necessary. ${ }^{54}$ This raised many concerns related to interventional treatment. In our analysis, CAVB was reported in 23 studies with a total of 47 cases (1.16\% of all patients). Unlike previous studies, the incidence of CAVB in our analysis was classified as transient and 
Mijangos-Vázquez et al ${ }^{8}$

Tanidir et al ${ }^{9}$

Shah et al ${ }^{10}$

Houeijeh et al ${ }^{11}$

Haddad et a ${ }^{12}$

Li et al ${ }^{13}$

Haddad et al ${ }^{14}$

Bu et al ${ }^{15}$

Kouakou et al16

Pillai et al ${ }^{17}$

Huang et al ${ }^{18}$

Shrestha et al ${ }^{19}$

Udink Ten Cate et al ${ }^{20}$

He et $\mathrm{al}^{21}$

Esmaeili et al ${ }^{22}$

Wang et $\mathrm{a}^{23}$

Park et al ${ }^{24}$

Ghosh et $\mathrm{al}^{25}$

Nguyen et $a^{26}$

Mandal et a ${ }^{27}$

Narin et a ${ }^{28}$

Zhao et al ${ }^{29}$

El Shedoudy et al ${ }^{30}$

He et $\mathrm{al}^{31}$

Lin et al ${ }^{32}$

Shyu et al ${ }^{33}$

El-Sisi et al ${ }^{34}$

Haas et al ${ }^{35}$

Zhou et a ${ }^{36}$

Hua et al ${ }^{37}$

Thakkar et al ${ }^{38}$

Polat et a ${ }^{39}$

Wang et al ${ }^{40}$

Bai et al ${ }^{41}$

Ghaderian et al ${ }^{42}$

Chen et al ${ }^{43}$

Ghaderian et al ${ }^{44}$

Chen et $\mathrm{a}^{45}$

Mahimarangaiah et al ${ }^{46}$

Kanaan et al ${ }^{47}$

Vijayalakshmi et al ${ }^{48}$

Narin et a ${ }^{49}$

Odemis et al ${ }^{50}$

Tzikas et al ${ }^{51}$

Overall $\left(I^{2}=0 \% ; P>0.99\right) \quad 0.003(0.001-0.005)$
$0 / 119$

$1 / 98$

$0 / 376$

$0 / 46$

$0 / 20$

$0 / 253$

$1 / 51$

$0 / 46$

$0 / 6$

$0 / 49$

$0 / 22$

$0 / 133$

$1 / 222$

$0 / 20$

$0 / 15$

$0 / 118$

$0 / 13$

$0 / 19$

$3 / 386$

$0 / 186$

$1 / 12$

$0 / 102$

$0 / 80$

$3 / 121$

$0 / 105$

$0 / 16$

$0 / 30$

$0 / 111$

$0 / 12$

$0 / 16$

$0 / 297$

$0 / 26$

$0 / 337$

$0 / 117$

$1 / 110$

$0 / 38$

$0 / 28$

$0 / 65$

$1 / 126$

$0 / 31$

$0 / 12$

$0 / 21$

$0 / 20$

$0 / 19$

$12 / 4050$

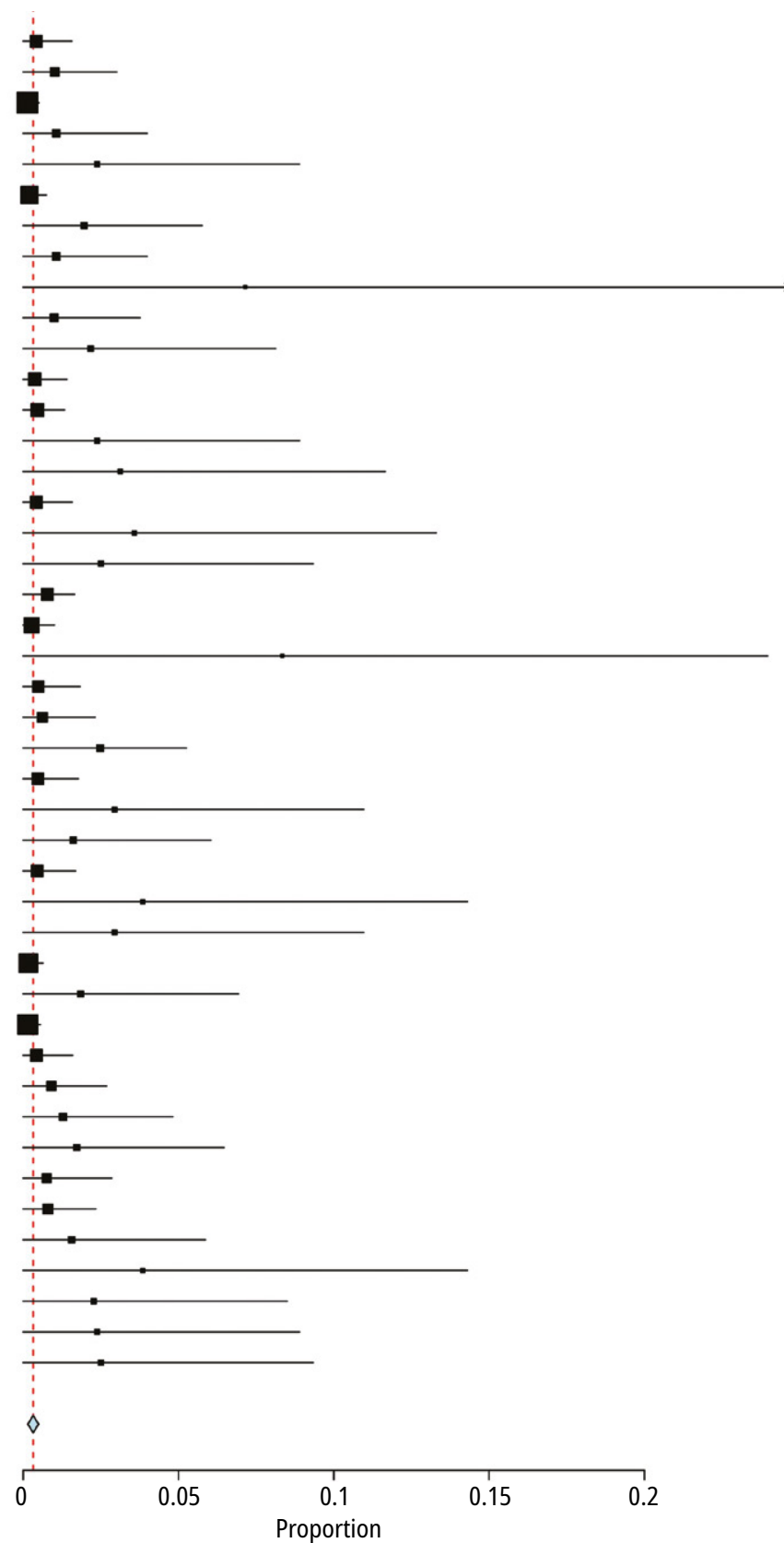

FIGURE 6 Forrest plot of permanent complete atrioventricular block occurrence Abbreviations: see FIGURE 3

TABLE 1 Presence of new-onset valvular lesions

\begin{tabular}{llll} 
Lesion & & $\begin{array}{l}\text { Early postprocedural } \\
\text { period }\end{array}$ & \multicolumn{1}{l}{$\begin{array}{l}\text { Last follow- } \\
\text {-up visit }\end{array}$} \\
\hline $\begin{array}{l}\text { Tricuspid valve } \\
\text { regurgitation }\end{array}$ & Mild or less severe & $76(1.88) ; 10$ & $74(1.83) ; 12$ \\
\cline { 2 - 4 } & At least moderate & $9(0.22) ; 5$ & $1(0.02) ; 1$ \\
\hline $\begin{array}{l}\text { Aortic valve } \\
\text { regurgitation }\end{array}$ & Mild or less severe & $53(1.31) ; 16$ & $48(1.19) ; 16$ \\
\cline { 2 - 4 } & At least moderate & $16(0.4) ; 9$ & $1(0.02) ; 1$ \\
\hline
\end{tabular}

Data are presented as number of patients (percentage of all participants included in the review); number of studies reporting event occurrence. chronic. The reason for such categorization was the fact that chronic $C A V B$ requiring pacemaker implantation is the clinically most serious condition. Also, most CAVBs in the reviewed studies were transient and often showed a good response to steroids. Other cases were resolved by surgical removal of the device and VSD closure. The pooled estimate rate for transient CAVB was $0.64 \%$ (95\% CI, 0.39-0.88), and for permanent CAVB, 0.32\% (95\% CI, 0.15-0.49). Santhanam et $\mathrm{al}^{3}$ noted CAVB in 120 patients (33 required pacemaker implantation) out of a total of 6762 patients, with the pooled incidence rate of $1.1 \%$. In another systematic 
review, Yang et $\mathrm{al}^{4}$ described 107 cases of CAVB in a population of 4406 patients, and 36 of the patients needed a pacemaker. Moreover, the authors estimated the overall pooled incidence rate of CAVB at $2.4 \%$ (95\% CI, 1.6-3.2). Numerous cases of resolved CAVB by the end of the follow-up period suggest that the reason for it is, at least in part, related to transient inflammation or edema at the site of device placement. The successful use of anti-inflammatory agents, such as steroids, in those cases further supports this hypothesis. ${ }^{4}$

Haas et $\mathrm{al}^{35}$ suggested that a specific spiral type of occluders, such as the NitOcclud Lê VSD coils, may pose a lower risk of causing CAVB (no case of permanent CAVB among 111 patients). What is more, this complication was not observed in the study by Houeijeh et $\mathrm{al}^{11}{ }^{11}$ in which the same devices were used. Due to difficulty in classifying the observed valvular lesions, data should be interpreted with caution. Very low incidence rates of tricuspid or aortic valve regurgitation are associated with restrictive criteria. However, the data on general permanent valvular disease presented by Santhanam et al $^{3}$ did not differ significantly from ours, and the overall incidence reported was $1.3 \%$ (95\% CI, 0.6-2.3).

Study limitations The generally variable quality of data reporting in the included studies made it difficult to assess their methodological quality and thereby judge their risk of bias. Regardless of our best efforts, as in all meta-analyses, inherent gaps in data presentation in individual studies constituted a limitation. Difficulties were encountered when classifying success and complication rates, as descriptions in articles were not always clear. Not every patient included in the review completed the planned follow-up. A large amount of data made the analysis challenging. Moreover, the study protocol was not registered. These limitations should be considered when making conclusions and establishing hypotheses for future research.

Conclusions Our review demonstrated that transcatheter closure of selected VSDs seems to be an effective and safe method of treatment. Recent studies have shown high rates of successful interventions with an acceptable incidence of complications. However, some dangerous events (eg, CAVB) are still possible. In this review, we attempted to summarize the latest (January 2014 to March 2020) data in the field of VSD interventional treatment. Admittedly, there are only a few analyses similar to ours and further research in the field is needed.

\section{SUPPLEMENTARY MATERIAL}

Supplementary material is available at www.mp.pl/kardiologiapolska.

\section{ARTICLE INFORMATION}

CONTRIBUTION STATEMENT PW and AR conceived the concept of the study. PS and AW searched and extracted relevant data. PS, AW, and PW performed the secondary selection of studies. PS conducted statistical analyses. PW critically revised the manuscript and contributed to data interpretation. All authors were involved in drafting and revising the text and approved the final version of the manuscript.

\section{CONFLICT OF INTEREST None declared.}

OPEN ACCESS This is an Open Access article distributed under the terms of the Creative Commons Attribution-NonCommercial-NoDerivatives 4.0 International License (CC BY-NC-ND 4.0), allowing third parties to download articles and share them with others, provided the original work is properly cited, not changed in any way, distributed under the same license, and used for noncommercial purposes only. For commercial use, please contact the journal office at kardiologiapolska@ptkardio.pl.

HOW TO CITE Weryński P, Skorek P, Wójcik A, et al. Recent achievements in transcatheter closure of ventricular septal defects: a systematic review of literature and a meta-analysis. Kardiol Pol. 2021; 79: 161-169. doi:10.33963/KP.15708

\section{REFERENCES}

1 Spicer DE, Hsu HH, Co-Vu J, Anderson RH, et al. Ventricular septal defect. Orphanet J Rare Dis. 2014; 9: 144

2 Schipper M, Slieker MG, Schoof PH, et al. Surgical repair of ventricular septal defect; contemporary results and risk factors for a complicated course. Pediatr Cardiol. 2017; 38: 264-270.

3 Santhanam H, Yang L, Chen Z, et al. A meta-analysis of transcatheter device closure of perimembranous ventricular septal defect. Int J Cardiol. 2017; 254: 75-83.

4 Yang L, Tai BC, Khin LW, et al. A systematic review on the efficacy and safety of transcatheter device closure of ventricular septal defects (VSD). J Interv Cardiol. 2014; 27: 260-272.

5 Moher D, Liberati A, Tetzlaff J, Altman DG. The PRISMA Group (2009). Preferred Reporting Items for Systematic Reviews and Meta-Analyses: the PRISMA Statement. Open Med. 2009; 3: 123-130.

6 Van Houwelingen HC. The role of empirical Bayes methodology as a leading principle in modern medical statistics. Biom J. 2014; 56: 919-932.

7 Byron W, Dahabreh I, Trikalinos T, et al. Closing the gap between methodologists and end-users: R as a computational back-end. J Stat Softw. 2012; 49: 1-15.

8 Mijangos-Vázquez R, El-Sisi A, Sandoval Jones IP, et al. Transcatheter closure of perimembranous ventricular septal defects using different generations of Amplatzer devices: multicenter experience. J Interv Cardiol. 2020; 2020: 8948249.

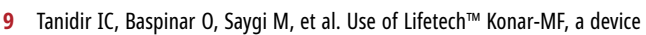
for both perimembranous and muscular ventricular septal defects: a multicentre study. Int J Cardiol. 2020; 310: 43-50.

10 Shah JH, Saraiya SP, Nikam TS, Jha M]. Transcatheter device closure of perimembranous ventricular septal defect in pediatric patients: long-term outcomes. Heart Views. 2020; 21: 17-21.

11 Houeijeh A, Godart F, Jalal Z, et al. Transcatheter closure of a perimembranous ventricular septal defect with Nit-0cclud Lê VSD Coil: a French multicentre study. Arch Cardiovasc Dis. 2020; 113: 104-112.

12 Haddad RN, Daou LS, Saliba ZS. Percutaneous closure of restrictive-type perimembranous ventricular septal defect using the new KONAR multifunctional occluder: midterm outcomes of the first middle-eastern experience. Catheter Cardiovasc Interv. 2020; 96: e295-e302.

13 Li H, Shi Y, Zhang S, et al. Short- and medium-term follow-up of transcatheter closure of perimembranous ventricular septal defects. BMC Cardiovasc Disord. 2019; $19: 222$.

14 Haddad RN, Daou L, Saliba Z. Device closure of perimembranous ventricular septal defect: choosing between Amplatzer occluders. Front Pediatr. 2019; 7: 300.

$15 \mathrm{Bu} \mathrm{H}$, Yang Y, Wu Q, et al. Echocardiography-guided percutaneous closure of perimembranous ventricular septal defects without arterial access and fluoroscopy. BMC Pediatr. 2019; 19: 302.

16 Kouakou NYN, Song J, Huh J, Kang IS. The experience of transcatheter closure of postoperative ventricular septal defect after total correction. J Cardiothorac Surg. 2019; 14: 104.

17 Pillai AA, Rangasamy S, Balasubramonian VR. Transcatheter closure of moderate to large perimembranous ventricular septal defects in children weighing 10 kilograms or less. World J Pediatr Congenit Heart Surg. 2019; 10: 278-285.

18 Huang $Y, Y a n X$, Lu L, et al. Transcatheter closure of doubly committed subarterial ventricular septal defects with the Amplatzer ductal occluder: initial experience. Cardiol Young. 2019; 29: 570-575.

19 Shrestha M, Promphan W, Layangool T, et al. Feasibility and 1-year outcome of transcatheter closure of perimembranous ventricular septal defects with different devices. Catheter Cardiovasc Interv. 2019 Jan 1; 93: e30-e37.

20 Udink Ten Cate FEA, Sobhy R, Kalantre A, et al. Off-label use of duct occluder devices to close hemodynamically significant perimembranous ventricular septal defects: a multicenter experience. Catheter Cardiovasc Interv. 2019; 93: 82-88.

21 He L, Du YJ, Cheng GS, Zhang YS. Safety of an improved patent ductus arteriosus occluder for transcatheter closure of perimembranous ventricular septal defects with abnormally attached tricuspid chordae tendineae. WJCC. 2019; 7: 562-571. 
22 Esmaeili A, Behnke-Hall K, Schrewe R, Schranz D. Percutaneous closure of perimembranous ventricular septal defects utilizing almost ideal Amplatzer Duct Occluder II: why limitation in sizes? Congenit Heart Dis. 2019; 14: 389-395.

23 Wang S, Ouyang W, Liu Y, et al. Transcatheter perimembranous ventricular septal defect closure under transthoracic echocardiographic guidance without fluoroscopy. J Thorac Dis. 2018; 10: 5222-5231.

24 Park H, Song J, Kim ES, et al. Early experiences using cocoon occluders for closure of a ventricular septal defect. J Cardiovasc Imaging. 2018; 26: 165-174.

25 Ghosh S, Sridhar A, Solomon N, Sivaprakasham M. Transcatheter closure of ventricular septal defect in aortic valve prolapse and aortic regurgitation. Indian Heart J. 2018; 70: 528-532.

26 Nguyen HL, Phan QT, Dinh LH, et al. Nit-Occlud Lê VSD coil versus duct occluders for percutaneous perimembranous ventricular septal defect closure. Congenit Heart Dis. 2018; 13: 584-593.

27 Mandal KD, Su D, Pang Y. Long-term outcome of transcatheter device closure of perimembranous ventricular septal defects. Front Pediatr 2018; 6: 128.

28 Narin N, Pamukcu 0, Tuncay A, et al. Percutaneous ventricular septal defect closure in patients under 1 year of age. Pediatr Cardiol 2018; 39: 1009-1015.

29 Zhao LJ, Han B, Zhang IJ, et al. Transcatheter closure of congenital perimembranous ventricular septal defect using the Amplatzer duct occluder 2. Cardiol Young. 2018; 28: 447-453.

30 El Shedoudy S, El-Doklah E. Mid-term results of transcatheter closure of ventricular septal defect using Nit-Occlud Lê ventricular septal defect coil, single-center experience. J Saudi Heart Assoc. 2019; 31: 78-87.

31 He L, Du Y], Cheng GS, Zhang YS. Safety of an improved patent ductus arteriosus occluder for transcatheter closure of perimembranous ventricular septal defects with abnormally attached tricuspid chordae tendineae. World J Clin Cases. $2019 ; 7$ : 562-571.

32 Lin MT, Chen CA, Hsu JY, et al. Transcatheter closure of perimembranous ventricular septal defects with amplatzer duct occluders. J Cardiol Cases. 2017; 10: 2227-2228.

33 Shyu TC, Lin MC, Quek YW, et al. Initial experience of transcatheter closure of subarterial VSD with the Amplatzer duct occluder. J Chin Med Assoc. 2017; 80: 487-491.

34 El-Sisi A, Sobhy R, Jaccoub V, Hamza H. Perimembranous ventricular septa defect device closure: choosing between amplatzer duct occluder I and II. Pediatr Cardiol. 2017; 38: 596-602

35 Haas NA, Kock L, Bertram H, et al. Interventional VSD-Closure with the Nit-Occlud $\circledast$ Lê VSD-Coil in 110 patients: early and midterm results of the EUREVECO -Registry. Pediatr Cardiol. 2017; 38: 215-227.

36 Zhou W, Li F, Fu L, et al. Clinical experience of transcatheter closure for residual ventricular septal defect in pediatric patients. Congenit Heart Dis. 2016; 11 : 323-331

37 Hua N, Aquino P, Owada CY. Transcatheter closure of perimembranous ventricular septal defects with the Amplatzer Vascular Plug-II. Cardiol Young. 2016; 26: 1194-1201.

38 Thakkar B, Patel N, Bohora S, et al. Transcatheter device closure of perimembranous ventricular septal defect in children treated with prophylactic oral steroids: acute and mid-term results of a single-centre, prospective, observational study. Cardiol Young. 2016; 26: 669-676.

39 Polat TB, Türkmen E. Transcatheter closure of ventricular septal defects using the Amplatzer Duct Occluder II device: a single-center experience. Adv Interv Cardiol. 2016; 12: 340-347.

40 Wang J, Zuo J, Yu S, et al. Effectiveness and safety of transcatheter closure of perimembranous ventricular septal defects in adults. Am J Cardiol. 2016; 117: 980-987.

41 Bai Y, Liu J, Qin YW, et al. Percutaneous closure of perimembranous ventricular septal defect with modified double-disk occluder: what is the outcome at 10-year follow-up? Congenit Heart Dis. 2016; 11: 45-51.

42 Ghaderian $\mathrm{M}$, Merajie $\mathrm{M}$, Mortezaeian $\mathrm{H}$, et al. Mid-term follow-up of the transcatheter closure of perimembranous ventricular septal defects in children using the Amplatzer. J Tehran Heart Cent. 2015; 10: 182-187.

43 Chen F, Li P, Liu S, et al. Transcatheter closure of intracristal ventricular septal defect with mild aortic cusp prolapse using zero eccentricity ventricular septal defect occluder. Circ J. 2015; 79: 2162-2168.

44 Ghaderian M, Merajie M, Mortezaeian $\mathrm{H}$, et al. Efficacy and safety of using Amplatzer Ductal Occluder for Transcatheter closure of perimembranous ventricular septal defect in pediatrics. Iran J Pediatr. 2015; 25: e386.

45 Chen GL, Li HT, Li HR, Zhang ZW. Transcatheter closure of ventricular septal defect in patients with aortic valve prolapse and mild aortic regurgitation: feasibility and preliminary outcome. Asian Pac J Trop Med. 2015; 8: 315-318.

46 Mahimarangaiah J, Subramanian A, Kikkeri Hemannasetty S, et al. Transcatheter closure of perimembranous ventricular septal defects with ductal occluders. Cardiol Young. 2015; 25: 918-926.

47 Kanaan $M$, Ewert $P$, Berger $F$, et al. Follow-up of patients with interventional closure of ventricular septal defects with Amplatzer Duct Occluder II. Pediatr. Cardiol. 2015; 36: 379-385.

48 Vijayalakshmi IB, Natraj Setty HS, Chitra N, et al. Amplatzer duct occluder II for closure of congenital Gerbode defects. Catheterization and Cardiovascular Interventions: SCAI. 2015; 86: 1057-1062.
49 Narin N, Baykan A, Pamukcu 0, et al. ADO II in percutaneous VSD closure in pediatric patients. J Interv Cardiol. 2015; 28: 479-484.

50 Odemis E, Saygi M, Guzeltas A, et al. Transcatheter closure of perimembranous ventricular septal defects using Nit-Occlud(®) Lê VSD coil: early and mid-term results. Pediatr Cardiol. 2014; 35: 817-823.

51 Tzikas A, Ibrahim R, Velasco-Sanchez D, et al. Transcatheter closure of perimembranous ventricular septal defect with the Amplatzer(®) membranous VSD occluder 2: initial world experience and one-year follow-up. Catheter Cardiovasc Interv. 2014; 83: 571-580.

52 Baumgartner H, De Backer J, Babu-Narayan SV, et al. 2020 ESC Guidelines for the management of adult congenital heart disease. Eur Heart J. 2020 Aug 29. [Epub ahead of print].

53 Yi K, You T, Ding ZH, et al. Comparison of transcatheter closure, mini-invasive closure, and open-heart surgical repair for treatment of perimembranous ventricular septal defects in children: a PRISMA-compliant network meta-analysis of randomized and observational studies. Medicine. 2018; 97: e12583.

54 Carminati M, Butera G, Chessa M, et al. Transcatheter closure of congenital ventricular septal defects: results of the European Registry. Eur Heart J. 2007; 28: 2361-2368. 